\title{
Controle do capim-braquiária associado à nutrição com boro no cultivo do mogno-africano em sistema silvipastoril ${ }^{1}$
}

\author{
Control of signal grass associated with boron nutrition in the cultivation of African \\ mahogany in a silvopastoral system
}

\author{
Alexandre Magno Brighenti²* e Marcelo Dias Muller ${ }^{2}$
}

\begin{abstract}
RESUMO - Dois experimentos foram conduzidos com o objetivo de avaliar o controle do capim-braquiária (Urochloa decumbens) nas linhas de plantio do mogno-africano (Khaya ivorensis) com aplicações de herbicidas isoladas ou combinadas com boro (B), bem como a resposta do mogno-africano a esse micronutriente. Ambos os experimentos foram implantados em delineamento experimental em blocos casualizados em parcelas subdivididas, com quatro repetições. Seis tratamentos foram aplicados nas parcelas: testemunha capinada; testemunha sem capina; glyphosate $\left(1.080 \mathrm{~g}\right.$ e.a. ha $\left.{ }^{-1}\right)+$ chlorimuronethyl $\left(10 \mathrm{~g}\right.$ i.a. ha $\left.{ }^{-1}\right)+0,05 \%$ v/v de óleo mineral, glyphosate $\left(1.080 \mathrm{~g}\right.$ e.a. ha- $\left.{ }^{-1}\right)+$ imazethapyr $\left(100 \mathrm{~g}\right.$ i.a. ha- $\left.{ }^{-1}\right)$, glyphosate $\left(1.080 \mathrm{~g}\right.$ e.a. ha $\left.{ }^{-1}\right)$ e oxyfluorfen (480 g i.a. ha $\left.{ }^{-1}\right)$. As subparcelas foram constituídas pela ausência ou presença de $4 \mathrm{~kg}$ de ácido bórico (17\% B) para 100 L de água. A associação do ácido bórico aos herbicidas glyphosate mais chlorimuron-ethyl, glyphosate mais imazethapyr, glyphosate ou oxyfluorfen não interfere no controle do capim-braquiária. A adição do ácido bórico à calda dos herbicidas proporciona incrementos nos teores de boro no solo e, consequentemente, aumento nos teores de boro nas folhas do mogno-africano.
\end{abstract}

Palavras-chave: Plantas daninhas. Urochloa decumbens. Micronutrientes. Integração lavoura-pecuária-floresta. Khaya ivorensis.

\begin{abstract}
Two experiments were carried out with the aim of evaluating the control of signal grass (Urochloa decumbens) in rows of African mahogany (Khaya ivorensis), by the application of herbicides, either alone or combined with boron (B), as well as the response of the African mahogany to this micronutrient. Both experiments were set up in an experimental design of randomized blocks and split-plot with four replications. Six treatments were applied to the plots: control with weeding, control with no weeding, glyphosate $\left(1,080 \mathrm{~g}\right.$ ae ha $\left.{ }^{-1}\right)+$ chlorimuron-ethyl $\left(10 \mathrm{~g} \mathrm{ai} \mathrm{ha}^{-1}\right)$ $+0.05 \% \mathrm{v} / \mathrm{v}$ mineral oil, glyphosate $\left(1,080 \mathrm{~g} \mathrm{ae} \mathrm{ha}^{-1}\right)+\operatorname{imazethapyr}\left(100 \mathrm{~g}\right.$ ai ha $\left.{ }^{-1}\right)$, glyphosate $\left(1,080 \mathrm{~g}\right.$ ae ha $\left.{ }^{-1}\right)$, and oxyfluorfen $\left(480 \mathrm{~g}_{\text {ai ha }}{ }^{-1}\right)$. The subplots consisted of the absence or presence of $4 \mathrm{~kg}$ of boric acid $(17 \% \mathrm{~B})$ in $100 \mathrm{~L}$ of water. Associating the boric acid with the herbicides, glyphosate plus chlorimuron-ethyl, glyphosate plus imazethapyr, glyphosate or oxyfluorfen does not interfere in the control of signal grass. The addition of boric acid to the herbicide solution results in increases in the levels of boron in the soil and a consequent increase in the boron content of the leaves of African mahogany.
\end{abstract}

Key words: Weeds. Urochloa decumbens. Micronutrients. Crop-livestock-forest integration. Khaya ivorensis.

\footnotetext{
*Autor para correspondência

${ }^{1}$ Recebido para publicação em 30/09/2013; aprovado em 22/05/2014

Trabalho financiado pela Fundação de Amparo a Pesquisa do Estado de Minas Gerais/FAPEMIG e pelo CNPq

${ }^{2}$ Embrapa Gado de Leite, Juiz de Fora-MG, Brasil, alexandre.brighenti@embrapa.br, marcelo.muller@embrapa.br
} 


\section{INTRODUÇÃO}

O sistema silvipastoril (SSP) vem obtendo destaque como alternativas de melhorias das propriedades físicas e químicas do solo (NEVES et al., 2009), no valor nutricional da forragem e no desempenho animal (PACIULLO et al., 2011), além da possibilidade de redução dos riscos financeiros e agregação de renda (MÜLLER et al., 2011).

O SSP tem se expandido para várias regiões do Brasil, cultivadas na sua grande maioria com pastagens, principalmente, as do gênero Urochloa. Espécies como o capim-braquiária (Urochloa decumbens), devido a sua agressividade, tornou-se uma das plantas mais competitivas no momento da implantação do componente florestal (TOLEDO et al., 1996).

Assim, o controle químico dessas espécies daninhas em sistemas integrados tem sido viável e primordial para o estabelecimento das espécies em consórcio. Dessa forma, os herbicidas mais empregados em sistemas florestais têm sido o oxyfluorfen, o glyphosate e o isoxaflutole. Contudo, esses produtos são recomendados para o cultivo do eucalipto e do Pinus (RODRIGUES; ALMEIDA, 2005), não havendo informações para espécies florestais de introdução recente como o mogno-africano (Khaya ivorensis).

O mogno-africano tem despertado a atenção de empresários e produtores nacionais em razão do incremento gradual da utilização de madeiras em serrarias. Além disso, o mogno-africano tem alcançado alto valor econômico internacional, sobretudo pela qualidade da madeira, beleza, durabilidade, crescimento relativamente rápido, resistência à broca do ponteiro (Hypsipyla grandella Zeller), bem como a excelente usinagem da madeira (CARVALHO et al., 2010; PINHEIRO et al., 2011).

Outro ponto que deve ser considerado na implantação e condução de povoamentos florestais é o aspecto relacionado à nutrição mineral das plantas. A atenção deve estar voltada não só para os macronutrientes, mas também para os micronutrientes. Entretanto, dentre os micronutrientes, o boro (B) é aquele que mais frequentemente se apresenta deficiente nos solos do Brasil. A falta de B resulta em inibição do crescimento das plantas, devido ao fato deste micronutriente fazer parte da parede celular. Na sua ausência, ocorre redução na síntese de pectina, celulose e lignina na parede das células do lenho, tornando-as mais finas (EPSTEIN; BLOOM, 2005). Também pode ocorrer inibição da elongação das raízes, em razão de distúrbios que ocorrem na divisão celular e na elongação das células (MARSCHNER, 1995).
Sintomas de deficiência de boro foram observados em várias outras espécies florestais como, por exemplo o eucalipto (SGARBI et al., 1999), levando a depreciação do produto no momento da comercialização como madeira para serraria (LEHTO et al., 2010). Para espécies do gênero Khaya, especificamente, os mognos-africanos, ainda existe muito pouco conhecimento a respeito de sua nutrição mineral (JEYANNY et al., 2009).

Assim, operações que possam simultaneamente controlar as plantas daninhas e, ao mesmo tempo, fornecer boro às plantas, permitem reduzir os custos de produção, além de favorecer o estabelecimento inicial de povoamentos florestais.

Esse estudo foi realizado com o objetivo de avaliar o uso isolado ou combinado de herbicidas e boro no controle do capim-braquiária nas linhas de cultivo do mogno-africano, bem como a resposta do mogno-africano a esse micronutriente.

\section{MATERIAL E MÉTODOS}

O local de implantação dos experimentos foi o município de Coronel Pacheco, MG (2132'17' S de latitude e $43^{\circ} 14^{\prime} 30^{\prime \prime} \mathrm{W}$ de longitude). O clima da região de acordo com a classificação de Köppen é do tipo Cwa (mesotérmico), definido como subtropical, chuvoso no verão e seco no inverno. A pluviosidade média anual é de aproximadamente $1.500 \mathrm{~mm}$.

O solo é classificado como Latossolo Vermelho Amarelo com 5,7 e 5,9 pH $\left(\mathrm{H}_{2} \mathrm{O}\right), 1,3$ e $1,7 \mathrm{mg} \mathrm{dm}^{-3} \mathrm{de}$ P, 17 e $23 \mathrm{mg} \mathrm{dm}^{-3}$ de K, 0,1 e $0,4 \mathrm{cmol}_{\mathrm{c}} \mathrm{dm}^{-3}$ de Ca e 0,17 e $0,19 \mathrm{mg} \mathrm{dm}^{-3} \mathrm{de} B$ para os experimentos 1 e 2 , respectivamente.

Para ambos os experimentos, utilizaram-se o delineamento experimental em blocos casualizados em parcelas subdivididas, com quatro repetições. Os tratamentos aplicados nas parcelas foram: testemunha capinada (TC); testemunha sem capina (TSC); glyphosate $\left(1.080 \mathrm{~g}\right.$ e.a. ha $\left.{ }^{-1}\right)+$ chlorimuron-ethyl $(10 \mathrm{~g}$ i.a. ha $\left.^{-1}\right)+0,05 \%$ v/v de óleo mineral (GC), glyphosate $\left(1.080\right.$ g e.a. ha $\left.{ }^{-1}\right)+$ imazethapyr $\left(100\right.$ g i.a. ha $\left.{ }^{-1}\right)(\mathrm{GI})$,

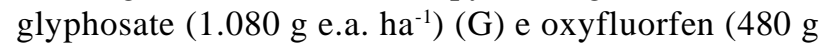
i.a. $\left.\mathrm{ha}^{-1}\right)(\mathrm{O})$. As subparcelas foram constituídas pela ausência ou presença de $4 \mathrm{~kg}$ de ácido bórico (17\% B) para $100 \mathrm{~L}$ de água. A área utilizada para a implantação dos experimentos foi cultivada anteriormente com pastagem de capim-braquiária (U. decumbens).

Sete dias antes do plantio do mogno-africano, o capim-braquiária foi dessecado em faixas de $3 \mathrm{~m}$ de largura utilizando o herbicida glyphosate $\left(1.440 \mathrm{~g}\right.$ e.a. ha $\left.{ }^{-1}\right)$. As 
covas foram abertas com moto-coveadora com $0,40 \mathrm{~m}$ de profundidade por $0,20 \mathrm{~m}$ de diâmetro e adubadas com $100 \mathrm{~g} \mathrm{cova}^{-1}$ da formulação NPK (08-28-16). Cada subparcela foi constituída de quatro plantas de mognoafricano, plantadas em 22/11/2011 (início do período das águas - Experimento 1) e em 27/01/2012 (meados do período das águas - Experimento 2). O espaçamento foi de $2 \mathrm{~m}$ entre plantas e $20 \mathrm{~m}$ entre fileiras (250 plantas $\mathrm{ha}^{-1}$ ), visando o manejo da área em SSP.

O preparo das caldas de pulverização e as aplicações dos tratamentos foram realizados em duas épocas: (27/12/2011 - Experimento 1) e (24/03/2012 - Experimento 2). Nessa época, as plantas de mognoafricano apresentavam altura média de $0,5 \mathrm{~m}$ e as plantas do capim-braquiária com $0,3 \mathrm{~m}$, em ambos os experimentos. Logo após o preparo das caldas de pulverização, amostras foram coletadas e levadas ao laboratório para determinação dos valores de $\mathrm{pH}$.

Um pulverizador experimental (Herbicat Ltda, Catanduva, SP, Brasil) foi utilizado na pulverização,

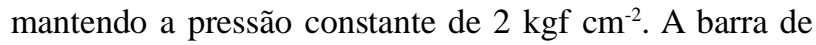
pulverização tinha 1,0 $\mathrm{m}$ de largura útil, com dois bicos de jato plano AVI 110 01, distanciados em $0,5 \mathrm{~m}$, e volume de pulverização equivalente a $90 \mathrm{~L} \mathrm{ha}^{-1}$. A aplicação foi realizada de forma dirigida sobre as plantas do capimbraquiária numa faixa de 1,0 m de cada lado das fileiras, sem atingir as plantas de mogno-africano.

Avaliou-se o efeito dos tratamentos sobre o capim-braquiária aos 7, 14 e 21 dias após a aplicação (DAA), utilizando a escala percentual de controle de 0 a 100\% (GAZZIERO et al., 1995). Além disso, avaliou-se aos 25 DAA, o teor de clorofila (índice SPAD - Soil Plant Analysis Development), utilizando o determinador de clorofila SPAD-502, Konica Minolta, Japão.

A fim de mensurar o efeito dos tratamentos no desenvolvimento das árvores, foi realizada, aos 150 DAA, uma avaliação em quatro plantas em cada subparcela medindo-se o diâmetro do coleto com uma fita métrica e a altura total do mogno-africano com uma régua telescópica graduada.

Em ambos os experimentos, foram retiradas amostras de cada subparcela nas profundidades de 0-10, 10-20 e 20-40 cm, aos 120 DAA, para análise dos teores de boro no solo. As determinações foram feitas em $\mathrm{BaCl}_{2}$ a $5 \mathrm{mmol} \mathrm{L}^{-1}$.

Foram coletadas, aos 150 DAA, as folhas do quarto ramo a partir do ápice das plantas em quatro árvores por subparcela a fim de determinar os teores de boro nos tecidos. O material foi colocado em sacos de papel kraft e, em seguida, levado para secar em estufa de ventilação forçada de ar a $65^{\circ} \mathrm{C}$, até atingir massa constante. As determinações de boro foram feitas por digestão via seca e posterior solubilização das cinzas com ácido clorídrico $50 \%$ (6 mol L $\left.{ }^{-1}\right)$. Em seguida, a concentração de B nos extratos foi determinada por espectrofotometria de emissão por plasma induzido.

As análises estatísticas foram realizadas utilizando o programa SAEG (RIBEIRO JÚNIOR, 2001). Os dados foram submetidos à análise de variância e as médias comparadas pelo teste ScottKnott, a 5\% de probabilidade.

\section{RESULTADOS E DISCUSSÃO}

Não houve interação significativa entre os fatores tratamentos de controle do capim-braquiária e a adição ou não da fonte de boro para as variáveis percentagem de controle aos 7, 14 e 21 DAA, índice SPAD, diâmetro do coleto e altura das plantas de mogno-africano (Tabelas 1 e 2).

Nos tratamentos em que foi aplicado o herbicida glyphosate, observou-se controle do capim-braquiária de, aproximadamente, $73 \%$ (Experimento 1) e 68\% (Experimento 2), aos 7 DAA. Os sintomas de injúria caracterizavam-se por clorose inicial, com agravamento dos sintomas aos 14 DAA e evolução para necrose. Na avaliação final de controle, aos 21 DAA, o percentual atingiu valores que variaram de $97 \%$ a $100 \%$, para ambos os experimentos. A adição do ácido bórico à calda com os herbicidas não interferiu no controle do capim-braquiária, não havendo diferença significativa entre os tratamentos onde os herbicidas foram aplicados isoladamente ou em combinação com a fonte de boro.

A adição do glyphosate a água para pulverização dos tratamentos reduziu o $\mathrm{pH}$ de aproximadamente 6,7 (água pura) para 4,8. Ao adicionar o ácido bórico, houve ainda um decréscimo para 4,4.

Essa redução no pH não interferiu no controle das plantas de capim-braquiária quando comparada aos tratamentos que receberam somente o glyphosate. A fitotoxicidade do glyphosate é afetada por mudanças no pH da solução de pulverização (WILLS; McWHORTER, 1985). A acidificação da calda reduz a dissociação das moléculas, facilitando a absorção do herbicida pelas plantas daninhas (WANAMARTA; PENNER, 1989).

Os valores referentes ao teor de clorofila (índice SPAD), ao diâmetro do coleto e à altura de plantas não sofreram influência da adição do ácido bórico à calda de pulverização quando comparados à aplicação sem a fonte de boro (Tabelas 1 e 2). 
Tabela 1 - Percentagem de controle do capim-braquiária aos 7, 14 e 21 dias após a aplicação dos tratamentos (DAA), teor de clorofila (índice SPAD), diâmetro do coleto (D) $(\mathrm{cm})$ e altura $(\mathrm{H})(\mathrm{m})$ de plantas de mogno-africano, em função dos tratamentos. (Experimento 1)

\begin{tabular}{lcrrrrrr}
\hline \multirow{2}{*}{ Tratamentos } & \multirow{2}{*}{ Ácido bórico } & \multicolumn{3}{c}{ Controle (\%) } & \multirow{2}{*}{ SPAD } & D & H \\
\cline { 2 - 5 } TC & Sem & 100,0 & 100,0 & 100,0 & 0,0 & 14,3 & 4,6 \\
\multirow{2}{*}{ TSC } & Com & 100,0 & 100,0 & 100,0 & 0,0 & 12,0 & 4,6 \\
& Sem & 0,0 & 0,0 & 0,0 & 54,0 & 10,1 & 3,4 \\
GC & Com & 0,0 & 0,0 & 0,0 & 54,3 & 11,8 & 4,3 \\
& Sem & 73,3 & 85,0 & 99,0 & 5,7 & 9,7 & 3,7 \\
GI & Com & 74,6 & 84,6 & 99,0 & 7,0 & 11,1 & 4,1 \\
& Sem & 73,0 & 83,6 & 98,6 & 9,1 & 10,7 & 3,9 \\
G & Com & 73,3 & 84,3 & 98,3 & 8,2 & 12,3 & 4,4 \\
& Sem & 71,3 & 84,6 & 99,0 & 6,3 & 13,2 & 4,5 \\
O & Com & 72,0 & 83,3 & 98,6 & 5,4 & 11,0 & 5,0 \\
& Sem & 41,0 & 65,3 & 75,6 & 8,1 & 14,0 & 6,1 \\
\hline
\end{tabular}

Tabela 2 - Percentagem de controle do capim-braquiária aos 7, 14 e 21 dias após a aplicação dos tratamentos (DAA), teor de clorofila (índice SPAD), diâmetro do coleto $(\mathrm{D})(\mathrm{cm})$ e altura $(\mathrm{H})(\mathrm{m})$ de plantas de mogno-africano, em função dos tratamentos. (Experimento 2)

\begin{tabular}{|c|c|c|c|c|c|c|c|}
\hline \multirow{2}{*}{ Tratamentos } & \multirow{2}{*}{ Ácido bórico } & \multicolumn{3}{|c|}{ Controle (\%) } & \multirow{2}{*}{ SPAD } & \multirow{2}{*}{$\mathrm{D}$} & \multirow{2}{*}{$\mathrm{H}$} \\
\hline & & $7 \mathrm{DAA}$ & $14 \mathrm{DAA}$ & $21 \mathrm{DAA}$ & & & \\
\hline \multirow{2}{*}{$\mathrm{TC}$} & Sem & 100,0 & 100,0 & 100,0 & 0,0 & 8,6 & 3,9 \\
\hline & Com & 100,0 & 100,0 & 100,0 & 0,0 & 8,8 & 3,4 \\
\hline \multirow{2}{*}{ TSC } & Sem & 0,0 & 0,0 & 0,0 & 52,6 & 9,3 & 3,6 \\
\hline & Com & 0,0 & 0,0 & 0,0 & 51,3 & 11,4 & 4,9 \\
\hline \multirow{2}{*}{ GC } & Sem & 67,3 & 81,6 & 98,6 & 9,5 & 10,4 & 4,1 \\
\hline & Com & 67,6 & 81,6 & 97,6 & 10,1 & 6,5 & 4,9 \\
\hline \multirow{2}{*}{ GI } & Sem & 68,6 & 83,6 & 98,3 & 9,8 & 9,9 & 3,8 \\
\hline & Com & 68,6 & 83,0 & 97,6 & 9,4 & 11,2 & 3,7 \\
\hline \multirow{2}{*}{ G } & Sem & 68,0 & 83,6 & 99,3 & 10,5 & 10,0 & 3,6 \\
\hline & Com & 67,6 & 83,6 & 100,0 & 10,2 & 10,2 & 3,9 \\
\hline \multirow{2}{*}{$\mathrm{O}$} & Sem & 40,6 & 57,3 & 76,6 & 7,5 & 10,1 & 3,7 \\
\hline & Com & 40,0 & 57,6 & 76,0 & 7,1 & 9,4 & 3,3 \\
\hline
\end{tabular}

Em ambos os experimentos, houve interação significativa entre os fatores tratamentos de controle do capimbraquiária e adição ou não da fonte de boro para as variáveis teores de boro nas duas primeiras profundidades do solo e nas folhas das plantas de mogno-africano (Tabelas 3 e 4).

Em relação ao conteúdo de $\mathrm{B}$ no solo à profundidade de $0-10 \mathrm{~cm}$ e nos tratamentos sem a adição de $\mathrm{B}$, o valores foram, em média, 0,37 e $0,29 \mathrm{mg} \mathrm{dm}^{-3}$, para os Experimentos
1 e 2, respectivamente. Contudo, nos tratamentos que receberam a fonte de boro, os valores foram 0,83 e 0,77 $\mathrm{mg} \mathrm{dm}{ }^{-3}$, para os Experimentos $1 \mathrm{e} 2$, respectivamente.

O fluxo em massa é o mecanismo predominante para o transporte de boro no solo (MATTIELO et al., 2009). E, a difusão é um mecanismo complementar, de importância relativa maior, em solos pobres desse micronutriente e em períodos de déficit hídrico. 
Tabela 3 - Teor de boro no solo $\left(\mathrm{mg} \mathrm{dm}^{-3}\right)$ nas profundidades de 0-10, 10-20 e 20-40 $\mathrm{cm}$ e nas folhas das plantas de mognoafricano (BF) $\left(\mathrm{mg} \mathrm{kg}^{-1}\right)$, em função dos tratamentos (Experimento 1$)^{(1)}$

\begin{tabular}{lccccc}
\hline \multirow{2}{*}{ Tratamentos } & \multirow{2}{*}{ Ácido bórico } & \multicolumn{3}{c}{ Boro no solo } & \multirow{2}{*}{ BF } \\
\cline { 3 - 5 } TC & Sem & $0-10$ & $10-20$ & $20-40$ & $35,8 \mathrm{~A}$ \\
& Com & $0,92 \mathrm{~A}$ & $0,38 \mathrm{~B}$ & 0,06 & $47,2 \mathrm{~A}$ \\
\multirow{2}{*}{ TSC } & Sem & $0,45 \mathrm{~B}$ & $0,74 \mathrm{~A}$ & 0,07 & $24,2 \mathrm{~B}$ \\
& Com & $0,93 \mathrm{~A}$ & $0,77 \mathrm{~A}$ & 0,03 & $48,2 \mathrm{~A}$ \\
$\mathrm{GC}$ & Sem & $0,33 \mathrm{~B}$ & $0,32 \mathrm{~B}$ & 0,03 & $32,0 \mathrm{~B}$ \\
& Com & $0,81 \mathrm{~A}$ & $0,50 \mathrm{~A}$ & 0,02 & $49,4 \mathrm{~A}$ \\
$\mathrm{GI}$ & Sem & $0,38 \mathrm{~B}$ & $0,28 \mathrm{~B}$ & 0,02 & $27,5 \mathrm{~B}$ \\
& Com & $0,77 \mathrm{~A}$ & $0,65 \mathrm{~A}$ & 0,04 & $46,0 \mathrm{~A}$ \\
$\mathrm{G}$ & Sem & $0,36 \mathrm{~B}$ & $0,26 \mathrm{~B}$ & 0,02 & $22,0 \mathrm{~B}$ \\
& Com & $0,86 \mathrm{~A}$ & $0,60 \mathrm{~A}$ & 0,03 & $57,6 \mathrm{~A}$ \\
$\mathrm{O}$ & Sem & $0,38 \mathrm{~B}$ & $0,31 \mathrm{~B}$ & 0,04 & $25,6 \mathrm{~B}$ \\
$\mathrm{CV}(\%)$ & Com & $0,69 \mathrm{~A}$ & $0,68 \mathrm{~A}$ & 0,04 & $47,6 \mathrm{~A}$ \\
\hline
\end{tabular}

${ }^{(1)}$ Médias seguidas pela mesma letra em cada coluna e para cada tratamento são iguais estatisticamente pelo teste Scott Knott, P $\leq 0,05$

Tabela 4 - Teor de boro no solo $\left(\mathrm{mg} \mathrm{dm}^{-3}\right)$ nas profundidades de 0-10, 10-20 e 20-40 $\mathrm{cm}$ e nas folhas das plantas de mogno-africano (BF) $\left(\mathrm{mg} \mathrm{kg}^{-1}\right)$, em função dos tratamentos (Experimento 2$)^{(1)}$

\begin{tabular}{|c|c|c|c|c|c|}
\hline \multirow{2}{*}{ Tratamentos } & \multirow{2}{*}{ Ácido bórico } & \multicolumn{3}{|c|}{ Boro no solo } & \multirow{2}{*}{$\mathrm{BF}$} \\
\hline & & $0-10$ & $10-20$ & $20-40$ & \\
\hline \multirow{2}{*}{$\mathrm{TC}$} & Sem & $0,33 \mathrm{~B}$ & $0,10 \mathrm{~B}$ & 0,05 & $26,3 \mathrm{~B}$ \\
\hline & Com & $0,75 \mathrm{~A}$ & $0,22 \mathrm{~A}$ & 0,06 & $38,6 \mathrm{~A}$ \\
\hline \multirow{2}{*}{ TSC } & Sem & $0,28 \mathrm{~B}$ & $0,09 \mathrm{~B}$ & 0,09 & $22,6 \mathrm{~B}$ \\
\hline & Com & $0,74 \mathrm{~A}$ & $0,28 \mathrm{~A}$ & 0,09 & $43,7 \mathrm{~A}$ \\
\hline \multirow{2}{*}{ GC } & Sem & $0,25 \mathrm{~B}$ & $0,08 \mathrm{~B}$ & 0,07 & $21,3 \mathrm{~B}$ \\
\hline & Com & $0,84 \mathrm{~A}$ & $0,32 \mathrm{~A}$ & 0,05 & $43,0 \mathrm{~A}$ \\
\hline \multirow{2}{*}{ GI } & Sem & $0,27 \mathrm{~B}$ & $0,03 \mathrm{~B}$ & 0,07 & $24,0 \mathrm{~B}$ \\
\hline & Com & $0,66 \mathrm{~A}$ & $0,38 \mathrm{~A}$ & 0,02 & $43,0 \mathrm{~A}$ \\
\hline \multirow{2}{*}{ G } & Sem & $0,29 \mathrm{~B}$ & $0,06 \mathrm{~B}$ & 0,07 & $23,3 \mathrm{~B}$ \\
\hline & Com & $0,86 \mathrm{~A}$ & $0,24 \mathrm{~A}$ & 0,10 & $42,6 \mathrm{~A}$ \\
\hline \multirow{2}{*}{$\mathrm{O}$} & Sem & $0,33 \mathrm{~B}$ & $0,05 \mathrm{~B}$ & 0,12 & $24,0 \mathrm{~B}$ \\
\hline & Com & $0,82 \mathrm{~A}$ & $0,32 \mathrm{~A}$ & 0,10 & $44,0 \mathrm{~A}$ \\
\hline $\mathrm{CV}(\%)$ & & 15,8 & 19,9 & - & 5,8 \\
\hline
\end{tabular}

${ }^{(1)}$ Médias seguidas pela mesma letra em cada coluna e para cada tratamento são iguais estatisticamente pelo teste $\mathrm{Scott}$ Knott, $\mathrm{P} \leq 0,05$

Parte do boro que é adicionado ao solo como fertilizante permanece solúvel e pode ser lixiviado no perfil (ROSOLEM; BISCARO, 2007). E ainda, o B que não está em solução, pode ser dessorvido e lixiviado
(COMMUNAR; KEREN, 2007). Esse fato foi observado nos experimentos, pois foi possível detectar a presença de B também na profundidade de $10-20 \mathrm{~cm}$. Nos tratamentos que receberam o ácido bórico, os valores de boro 
alcançaram 0,65 $\mathrm{mg} \mathrm{dm}^{-3}$ (Experimento 1) e 0,29 $\mathrm{mg} \mathrm{dm}^{-3}$ (Experimento 2) e naqueles sem a presença do ácido bórico os valores foram 0,31 e $0,06 \mathrm{mg} \mathrm{dm}^{-3}$, respectivamente. Entretanto, dentro do período de avaliações, não foi possível detectar diferenças significativas entre os tratamentos na ausência ou na presença da fonte de boro na profundidade de $20-40 \mathrm{~cm}$ do perfil do solo. Possivelmente, não houve tempo suficiente para o boro ser lixiviado até a profundidade de $20-40 \mathrm{~cm}$ dentro do período de avaliação dos experimentos.

O boro adicionado ao solo foi absorvido pelas plantas de mogno-africano. Os teores de B nos tratamentos que não receberam o ácido bórico foram inferiores aos tratamentos com a fonte de boro. Os teores de B foram, em média, 27,85 e $23,58 \mathrm{mg} \mathrm{kg}^{-1}$ para os tratamentos na ausência de boro e 49,33 e 42,48 $\mathrm{mg} \mathrm{kg}^{-1}$ para os tratamentos na presença da fonte de $\mathrm{B}$ nos experimentos 1 e 2 , respectivamente.

O boro é um micronutriente essencial e deve estar prontamente disponível uma vez que possui funções indispensáveis ao crescimento e ao desenvolvimento das plantas. Ele está envolvido em processos fisiológicos como, por exemplo, a síntese e a estruturação da parede celular, sendo integrante da hemicelulose. Participa do transporte de açúcares através da membrana, na incorporação de fosfato na formação de nucleotídeos, no desenvolvimento do tubo polínico e na frutificação (DECHEN; NACHTIGALL, 2006). Além disso, está envolvido no metabolismo do ácido indolacético, no metabolismo fenólico e do RNA, na respiração, na divisão celular e na estruturação das células-guarda (MARSCHNER, 1995; SHORROCKS, 1997).

A maior concentração de B nas folhas de mognoafricano evita o surgimento de alterações anatômicas, fisiológicas e bioquímicas nas plantas, prevenindo o aparecimento de manchas foliares necróticas, alterações nos tecidos internos da parte superior do caule e ainda prejuízos ao processo de floração e frutificação.

\section{CONCLUSÕES}

1.A associação do ácido bórico aos herbicidas glyphosate mais chlorimuron-ethyl, glyphosate mais imazethapyr, glyphosate ou oxifluorfen não interfere no controle do capim-braquiária;

2.A adição do ácido bórico à calda dos herbicidas proporciona incrementos nos teores de boro no solo e, consequentemente, aumento nos teores de boro nas folhas do mogno-africano.

\section{AGRADECIMENTOS}

À Fundação de Amparo à Pesquisa do Estado de Minas Gerais e ao Conselho Nacional de Desenvolvimento Científico e Tecnológico, pelo apoio financeiro.

\section{REFERÊNCIAS}

CARVAlHO, A. M. et al. Avaliação da usinagem e caracterização das propriedades físicas da madeira de mogno africano (Khaya ivorensis A. Chev.). Cerne, v. 16, p. 106114, 2010. Suplemento.

COMMUNAR, G.; KEREN, R. Effect of transient irrigation on boron transport in the soil. Soil Science Society of American Journal, v. 71, n. 2, p. 306-313, 2007.

DECHEN, A. R.; NACHTIGALL, G. R. Micronutrients. In: FERNANDES, M. F. (Ed.). Nutrição mineral de plantas. Viçosa. Sociedade Brasileira de Ciência do Solo, 2006. p. 227354.

EPSTEIN, E.; BLOOM, A. J. Mineral nutrition of plants: principles and perspectives. Sunderland: Sinauer Associates, 2005. $400 \mathrm{p}$.

GAZZIERO, D. L. P. et al. Procedimentos para instalação, avaliação e análise de experimentos com herbicidas. Londrina: Sociedade Brasileira da Ciência das Plantas Daninhas, 1995. 42 p.

JEYANNY, V. et al. Effects of macronutrient deficiencies on the growth and vigour of Khaya ivorensis seedlings. Journal of Tropical Forest Science, v. 21, n. 2, p. 73-80, 2009.

LEHTO, T. et al. Boron in forest trees and forest ecosystems. Forest Ecology and Management, v. 260, n. 12, p. 20532069, 2010.

MARSCHNER, H. Mineral nutrition of higher plants. 2. ed. London: Academic Press, 1995. 889 p.

MATTIELlO, E. M. et al. Transporte de boro no solo e sua absorção por eucalipto. Revista Brasileira de Ciência do Solo, v. 33, n. 5, p. 1281-1290, 2009.

MÜLLER, M. D. et al. Economic analysis of an agrosilvipastoral system for a mountainous area in Zona da Mata Mineira, Brazil. Pesquisa Agropecuária Brasileira, v. 46, n. 10, p. 1148-1153, 2011.

NEVES, C. M. N. et al. Indicadores biológicos da qualidade do solo em sistema agrossilvipastoril no noroeste do estado de Minas Gerais. Ciência e Agrotecnologia, v. 33, n. 1, p. 105112, 2009.

PACIULLO D. S. C. et al. Performance of dairy heifers in a silvopastoral system. Livestock Science, v. 141, n. 2, p. 166172, 2011.

PINHEIRO, A. L. et al. Ecologia, silvicultura e tecnologia de utilização dos mognos-africanos (Khaya spp.). Viçosa, MG: Sociedade Brasileira de Agrossilvicultura, 2011.102 p. 
RIBEIRO JÚNIOR, J. I. Análises estatísticas no SAEG. Viçosa: Universidade Federal de Viçosa, 2001. 301 p.

RODRIGUES, B. N.; ALMEIDA, F. S. Guia de herbicidas. 5. ed. Londrina: Grafmark, 2005. 592 p.

ROSOLEM, C. A.; BISCARO, T. Adsorção e lixiviação de boro em Latossolo Vermelho-Amarelo. Pesquisa Agropecuária Brasileira, v. 42, n. 10, p. 1473-1478, 2007.

SHORROCKS, V. M. The occurrence and correction of boron deficiency. In: DELL, B.; BELL, W. (Ed.). Boron in soils and plants: reviews. Dordrecht Martinus: Nijhoff Publishers, 1997. p. 121-148.

SGARBI, F. et al. Crescimento e produção de biomassa de clone de Eucalyptus grandis x Eucalyptus urophylla em condições de deficiência de macronutrientes, B e Zn. Scientia Forestalis, n. 56, p. 69-82, 1999.

TOLEDO, R. E. B. et al. Comparação de custos de quatro métodos de manejo de Brachiaria decumbens Stapf em área de implantação de Eucalyptus grandis W. Hill ex Maiden. Revista Árvore, v. 20, n. 3, p. 319-330, 1996.

WANAMARTA, G.; PENNER D. Foliar absorption of herbicides. Review. Weed Science, v. 4, n. 1, p. 215-232, 1989.

WILLS, G. D.; McWHORTER, C. G. Effect of inorganic salts on the toxicity and translocation of glyphosate and MSMA in purple nutsedge (Cyperus rotundus). Weed Science, v. 33, n. 6, p. 755-761, 1985. 